\title{
PRENATAL ANTICONVULSANTS AND SMALL INFANT HEAD SIZE
}

Occipitofrontal head circumference (OFC) of 172 neonates exposed prenatally to phenobarbital and phenytoin was compared to 168 control neonates, and the findings were studied in relation to a follow-up assessment of cognitive functioning in adulthood, at the University of Amsterdam, The Netherlands. Prenatally phenobarbital + phenytoin - exposed neonates had a significantly smaller OFC than those exposed to phenobarbital monotherapy and controls $(0.7$ $\mathrm{cm}$ mean difference, $\mathrm{p}=0.003$ ). In follow-up as adults, no significant differences in cognitive functioning were determined in the three groups. However, persistent learning problems were evident in $12 \%$ of the exposed subjects versus $1 \%$ of the controls, and more of the exposed subjects were mentally retarded. Learning problems were not clearly related to small OFC, or maternal epilepsy. (Dessens $A B$, Cohen-Kettenis PT, Mellenbergh GJ et al. Association of prenatal phenobarbital and phenytoin exposure with small head size at birth and with learning problems. Acta Paediatr May 2000;89:533-541). (Respond: Dr AB Dessens, Delta Psychiatric Hospital, PO Box 800, 3170 DZ Poortugaal, The Netherlands).

COMMENT. Neonates exposed prenatally to PB + PHT polytherapy for maternal epilepsy have smaller head sizes than neonates exposed to PB monotherapy and controls. As adults, a higher number of subjects exposed to anticonvulsants have learning problems, but these are not necessarily correlated with the head circumference at birth.

In a commentary, Hansen D and Lou HC (Acta Paediatr May 2000;89:505-507) emphasize the frequency of conflicting results and methodological problems of studies of brain development and prenatal exposure to drugs. Women with seizures may have episodes of hypoxia that affect brain development, and those with refractory epilepsy are likely to receive polytherapies, more often complicated by fetal malformation.

\section{VALPROATE IN REFRACTORY STATUS EPILEPTICUS}

The results of treatment of refractory status epilepticus (SE) with IV valproate (VPA) in 41 children are reported from University Hospital for Children, Erlangen, Germany. Twenty two patients had previously received longterm antiepileptic therapy, whereas the SE was the initial presentation of a seizure disorder in 19. Initial treatment with diazepam, phenobarbital, and phenytoin had failed. The initial loading dose of IV VPA was 20 to $40 \mathrm{mg} / \mathrm{kg} / \mathrm{body}$ weight, diluted $1: 1$ with normal saline or $5 \%$ dextrose, and given over 1 to 5 minutes, repeated after 10 to 15 minutes if necessary. When seizures had ceased for 12 hours and the EEG was normalized, VPA dosage was reduced.

The response rate was $78 \%, 66 \%$ being controlled within 2 to 6 minutes. The highest success rate was obtained with dosages between 30 and $40 \mathrm{mg} / \mathrm{kg} / \mathrm{bwt}$, and correlated with higher VPA blood levels in immediate responders $(121+/-10$ $\mathrm{mg} / \mathrm{L}$ ) compared to levels of $93+/-6 \mathrm{mg} / \mathrm{L}$ in delayed responders. There were no VPA-related systemic side effects. (Uberall MA, Trollmann R, Wunsiedler U, Wenzel D. Intravenous valproate in pediatric epilepsy patients with refractory status epilepticus. Neurology June (1 of 2) 2000;54:2188-2189). (Reprints: Dr Michael A Uberall, Neuropediatric Department, University Hospital for Children and Adolescents, Loschgestrasse 15, D-91054 Erlangen, Germany).

COMMENT. IV valproate is an effective and well tolerated alternative therapy for refractory status epilepticus in children. 